\title{
The culture of the sharp pencil: Can a literacy intervention lever school change?
}

\author{
SALLY CURRIN Independent school consultant \\ ELIZABETH J PRETORIUS Department of Linguistics, University of \\ South Africa
}

\begin{abstract}
This article reports on a reading intervention project undertaken in a high poverty primary school in Gauteng where reading levels in both the home language, Northern Sotho, and in English were very low. Some of the factors associated with school effectiveness (SE) are first examined and thereafter the nature of the reading intervention programme is described. The project outcomes are presented and discussed against established SE factors and the high poverty ecological system within which the school operates. Although some of these outcomes are presented quantitatively, the article also considers some of the qualitative aspects of the intervention and its outcomes. Despite obstacles which lessen impact, it is concluded that a reading intervention in high poverty schools can simultaneously improve learner performance and the functioning of an ineffective school, but that such an intervention needs to adopt a multi-level ecological approach.
\end{abstract}

\section{Introduction}

"Many children use very short and blunt pencils. Some children have no pencils at all. Can they become literate if they don't have proper pencils?" These comments were made by the facilitator of a reading intervention project that was implemented in a high poverty primary school ${ }^{1}$. When this matter was raised at a feedback meeting with teachers at the school, considerable time was spent discussing the 'pencil problem'. Some teachers shrugged it off resignedly as a small detail, and some attributed the problem to the high levels of poverty in the school. Others pointed out the altruistic reason for the short pencils and explained that although learners often came to school with new pencils, they broke them in half or quarters to share with learners who did not have pencils. Towards the end of the discussion, the principal declared, "Yes, we're

${ }^{1}$ The project facilitator is also first author of this article. A similar observation was made in case studies of the reading practices of tertiary students who performed poorly (Pretorius 2005:801). 
a poor school, but we can't just leave this. Children must come to school with pencils!" The following week she visited several classrooms and tightened up general discipline in the school.

This incident is reminiscent in a small way of the 'broken window' phenomenon which refers to an approach adopted during former New York mayor Rudy Giuliani's term of office in the 1990s, to immediately replace broken windows on train carriages in an effort to bring down the crime rate. It was argued that if a place looked run down, then crime would be more likely to occur (Gladwell, 2001). Although the reasons for crime are more complex than the broken window theory suggests, it is instructive to reflect on the effect that small changes may bring about within a community. Short, blunt pencils may be pedagogical metaphors of educational dysfunction in the same way that broken carriage windows are seen to reflect urban dysfunction.

The national systemic evaluations that have been undertaken since 2001 have revealed severe dysfunction within our education system. For instance, the first round of Grade Three evaluations showed that learners achieved a national mean of $38 \%$ for reading and writing in their home language (Department of Education, 2003). Three years later, only $36 \%$ of Grade Six learners passed the literacy test in the language of learning and teaching (LoLT). In all, 63\% fell into the 'Not Achieved' band, while only $28 \%$ were functioning at or above grade level (Department of Education, 2005). Results such as these suggest a 'broken window' phenomenon within education. In order to address these educational challenges we need to be cognizant of the factors that underlie effective schools and identify those factors that help to make schools resilient despite the obstacles they face.

In this article we describe a reading intervention project in a high poverty school and reflect on the effect it had on a low functioning school community after three years of implementation. We also suggest modifications to the original intervention model to strengthen its potential impact on both reading outcomes and school effectiveness.

Although the focus of the intervention project is on reading, being literate involves more than mastery of the mechanical aspects of reading, important as these are; it requires the ability to perform a range of literate behaviours related to written language. These literate behaviours comprise a set of cognitive and linguistic accomplishments which develop within a specific sociocultural context which ascribes value to specific literacy behaviours and practices. Literacy is thus embedded within an ecological system that includes the family, the community and the broader culture, and it functions as an aspect of human activity rather than simply as a set of mechanical skills. 
The impact that the intervention project had on the reading skills of the learners has been documented from a more quantitative perspective elsewhere (e.g. Pretorius and Mampuru, 2007, Pretorius and Currin, 2010). In this article we report instead on the impact of the reading project from a more qualitative perspective, as an aspect of human activity within a high poverty ecology of schooling. Our data are sourced from field notes, classroom observations and interactions with educators and we reflect on processes as much as on products and outcomes. In order to situate the project within the broader socioeconomic and socioeducational contexts within which literacy is typically embedded, we first briefly look at the relationship between literacy and poverty and then provide a brief sketch of studies of school effectiveness. Thereafter we describe the project school and the nature of the intervention, and we sketch the reading situation prior to and during the implementation of the intervention programme.

\section{Poverty, literacy and school performance}

Poverty and poor schooling tend to go hand in hand. Poverty per se does not cause poor school performance. Instead, factors associated with poverty create barriers to learning in homes, schools and classrooms (e.g. Allington, 2000, Bradley and Corwin, 2002). For example, schools in poor areas tend to be under-resourced, so children do not have easy access to books that form the backbone of literacy development and academic performance. Poor schools tend to be poorly managed and have fewer qualified teachers. In addition, children in high poverty schools tend to come from homes where adult literacy levels are low and where expectations about children's progress may not be high. As a result, poor children often perform under par or drop out of school. Generally, learners who fare poorly on the educational ladder also fare poorly on the occupational ladder, which in turn has socioeconomic implications. Since current disparities in school accomplishment presage future socioeconomic disparities, it is important to provide good quality education for all. Given that about $80 \%$ of schools in South Africa are disadvantaged (Gustafsson, 2005), it is imperative to understand the nature and dynamics of school effectiveness and the relationship between poverty and school accomplishment.

Barriers to learning associated with poverty can be overcome if schools create conditions conducive to learning. A range of conditions, or School Effectiveness (SE) factors, have emerged from over forty years of research into school effectiveness in both rich and poor countries around the world (e.g. Harris, 1998, Gustafsson, 2005, Scheerens, 2000, Silins and Mulford, 2002). Identifying these factors is an important first step; knowing how to bring about 
concomitant changes in ineffective schools is the next demanding step, and knowing how to sustain the changes so that educational efficacy becomes the norm in schools is the final challenge. The outcomes of this reading project suggest an ecological approach which may hold some answers for school improvers faced with these challenges.

\section{Effective Schools}

An effective school is generally accepted as one which achieves its education goals. For the purposes of this article 'educational goals' are taken to be attainment of academic performance at a standard accepted within the school's educational system. Most SE studies have identified multiple, multi-level measures of school effectiveness. A review of the SE literature from affluent countries conducted by Harris (1998) revealed the following factors to be consistently associated with effective schools: purposeful, firm leadership with shared decision-making; effective management of people; co-operative and collaborative practices, with attendant responsibility of both teachers and pupils; balance between support and challenge; a learning climate; academic emphasis; parental involvement; and continual planning, implementing, monitoring and evaluating, with support.

As instructive as these factors are, it is argued that effectiveness indices in more affluent countries do not necessarily denote effectiveness in transitional or poorer contexts (Scheerens, 2000, 2001, Harber and Muthukrishna, 2000, Levin and Lockheed, 1993, Christie and Potterton, 1999). SE factors identified from a review of the literature relevant to transitional or poorer countries point to a range of factors such as basic organizational functionality; strong but democratic leadership and management; good governance; appropriate authority relations and discipline; safety and security; resources (these include basic needs, instructional materials, time for instruction and reading, teacher qualification and language competence, facilitating conditions); centrality of teaching and learning; focus on academic achievement; focus on learner needs; teacher professionalism, commitment, accountability, collegiality, the will to act, mutual respect, concern for all, a positive climate and high expectations; leadership density with vision; qualified, competent, motivated, hard-working, well-prepared teachers who manage their classrooms effectively; healthy social dynamics; small class sizes; effective monitoring and evaluation (homework and testing) and effective diagnostic analysis of results; integrated planning and co-ordination; an involved, helping relationship with the wider community including the parent body; and proficiency in the language of learning and teaching' (LoLT) (Christie, 1998, Christie and Potterton 1999, Muller and Roberts, 2000, Harber and Muthukrishna, 2000, Scheerens, 2001, Howie, 
2002, Jordaan, 2004, Department of Education, 2005). Taylor's overview (2007) of recent South African SE research studies reveals factors common to less affluent countries. It is instructive to note that frequent, adequate reading and writing homework emerges as an additional, crucial effectiveness factor.

\section{The intervention project}

\section{Rationale and aims of the intervention model}

In 2005 a multi-level, longitudinal reading project, 'Reading is FUNdamental', was introduced into Batho Pele Primary School' ${ }^{2}$. The overall aim of the project was to optimise the conditions that promote the development of sound reading so that reading could become - as the name indicates - an integral part of the daily activity of the school as well as a fun activity. It was hoped that by developing a culture of reading the school would improve the overall language and academic development of the learners. To this end a multi-level approach was adopted that emphasised the building up of resources as well as capacity and involved the participation of the learners, teachers and parents.

The focus during the first year was primarily on reading in the entry and exit phases, i.e., Grades One and Seven. During the second and third year the focus fanned out to include all the grades.

\section{The school context}

Batho Pele Primary School is one of the poorer performing primary schools in a township west of Pretoria. There are just over 600 learners, 16 teachers and 2 administrative personnel. Until the end of 2006, school fees were R120 per annum but only $40-50 \%$ of the parents actually paid the full school fees. In 2007, the school was assigned the status of a non-fee paying Quintile 1 school. ${ }^{3}$ The school has a feeding scheme, where 400 children ranging from Grades $\mathrm{R}$ to Seven are fed once a day.

There is one Grade $\mathrm{R}$ class but two classes at each subsequent grade level. Northern (N) Sotho is the language of learning and teaching from Grade R to Grade Three, after which English becomes the LoLT, with N Sotho a subject

\footnotetext{
${ }^{2}$ Not the real name of the school.

${ }^{3}$ State funding for schools is now based on a quintile system (there are five quintiles) according to socioeconomic indicators; Quintile 1 schools are the poorest and are supposed to get the biggest slice of the funding pie.
} 
from Grades Four to Seven. About 70-80\% of the learners come from primarily N Sotho speaking homes. ${ }^{4}$

At the start of the project there was fairly strong, democratic leadership by the principal, basic organisational functionality, a supportive governing body, a sense of safety and security, congenial relationships amongst staff and a keen desire to improve the school.

\section{Reading context prior to intervention}

On initial visits to the school by the project team, several teachers stated that many learners "couldn't read", although the nature of their reading problems were not specified. None of the classrooms were print-rich environments and were rather drab and tatty. Although older learners were issued with textbooks (for classroom use only), additional access to other books and material of an educational or recreational nature was non-existent. It appeared that literacy was primarily taught from the blackboard, homework was uncommon, and reading homework virtually nonexistent. Large classes were usual, for example, it was not uncommon for fifty-five Grade Seven learners to be packed into standard size rooms with undersized furniture. Mobility within the classroom was restricted and getting access to cupboards at the back of the classrooms was almost impossible.

Although a small room had been designated 'the library' it did not function as such. Instead, it was used as a storeroom-cum-office. It contained mainly old textbooks and some storybooks; there was no lending system. The library committee, appointed the previous year, had tried to "sort out" the library, but they felt overwhelmed by the task as none of them had any library expertise.

Of the sixteen teachers, thirteen have a post-Grade Twelve two-year primary school teacher's certificate qualification, and three have a postgraduate Honours degree (the principal, vice-principal and one of the $\mathrm{N}$ Sotho teachers). At the start of the project, none of the teachers was a member of a community library and eleven of the teachers (i.e. over 69\%) indicated that they had ten or fewer books in the home.

In order to determine existing entry and exit reading levels at the school and use these as a baseline for measuring reading progress, the literacy levels of Grade One students were assessed ( $\mathrm{N}$ Sotho) and the language and reading comprehension levels of all the Grade Seven learners were assessed in N Sotho and English. Literacy assessments were extended to Grade Six learners in the

${ }^{4}$ These figures vary from year to year and from class to class. 
second year. Due to space constraints only the Grade Seven assessments are presented here. It suffices at this point to state that initially, Grade Seven reading comprehension levels did not exceed 30\% in either N Sotho or English. In terms of reading accomplishment, this was not an effective school.

\section{Building up resources}

School library: The first step in building up the school library was to reclaim the library space (i.e. remove the storeroom and office functions), weed the library (i.e. sort through and discard old and inappropriate books), clean out the room, paint the walls and shelves a bright colour and install security bars on the windows. Teachers volunteered in the afternoons to help in the reclaiming process, which stretched over several weeks.

Because the teachers had heavy teaching schedules, a young man from the community was appointed as librarian and paid a monthly stipend from the project budget. A computer, printer, scanner and a library software programme were installed, and the librarian was trained on how to use the programme. New books in both English and N Sotho were purchased. All the books were catalogued, computerised, and arranged according to the Dewey system. Small plastic reading tables, chairs and a mat were also installed. The school's library committee was rekindled.

Classroom book corners: Besides the library, the school's resources were also enhanced by way of increasing print based materials in the classrooms. Teachers were made aware of the need to create print rich classroom environments. To this end, the Grade One teachers were encouraged to develop reading corners in their classrooms and were given a small library of 120 easy books in N Sotho (the READ Sunshine series, comprising twenty titles with six copies per title), a bookshelf and a small, child-size 'pouf' armchair. The teachers were encouraged to display more print material on the walls. Because much of the funding was allocated to purchasing books for the school library, reading books could not be purchased for all the classrooms. However, all the teachers were encouraged to create stimulating print environments for their classes.

\section{Building capacity}

Literacy resources have no value if not used properly. Teachers - and parents - need to be shown what to do with books. The intervention thus also focused on developing the instructional capacity of the teachers and the supportive capacity of the parents. 
Teacher capacity: Workshops of approximately $1 \frac{1 / 2}{2}$ hours were held fortnightly with the teachers after school. All the teachers were expected to attend and an attendance register was kept. The teachers were all issued with lever-arch files at the start of the project, handouts were given at the workshops, and the teachers were expected to 'build up' their reading files so that they could serve as a source of information on reading and library related matters. The presence of the principal at most of the workshops helped to ensure that management was conversant with the project and also conveyed the message that the project was being taken seriously.

The focus of the workshops was specifically on reading and information literacy (e.g. how the Dewey system works, how to find things in a library, how to do searches on the Internet, etc.). The aim was to increase teachers' understanding of the reading process, familiarise them with reading strategies, draw attention to the OBE assessment standards for reading and different ways of assessing reading at the various grade levels, and integrating the library into their classroom practices. Arrangements were also made for teachers to take turns, by prior appointment, to spend a morning observing good reading practice in a grade equivalent classroom in a highly effective school where reading is a priority.

In addition, two teachers per year were sponsored by the project to register for the UNISA certificate course in Parent Involvement. Two teachers graduated from the course each year and while they were doing the course they were expected to promote Parent Involvement in the school and equip parents for effective support of their children's education.

Parent capacity: The Family Literacy component: The teachers often commented that many parents regarded the school as being responsible for their children's schooling, and consequently did not get involved in their children's school activities. Parents with low literacy levels may also be disinclined to help their children in an area in which they perceive themselves to lack skills. A family literacy component was thus included in the project to involve parents more actively in the literacy development of their children.

A series of Family Literacy workshops were held for Foundation Phase and Intersen (i.e. Grades Four to Seven) parents respectively. These workshops were held on Sunday mornings at the school (the only day available for parents to attend school related activities), and refreshments served afterwards. The principal and teachers at the relevant grade levels also attended the workshops.

The aim of these workshops was to draw parents' attention to the importance of reading and to encourage them to read to their children and/or to listen 
to their children reading. A twenty-minute video in $\mathrm{N}$ Sotho on how to read storybooks to children was also shown. Other topics were also covered, such as taking an interest in children's school activities, making time and space available in the home for homework, encouraging membership of the local community library, monitoring what and how much TV children watch, and ensuring that children go to bed at appropriate hours. The head librarian at the local community library was also invited to address the parents. Handouts were given in both English and N Sotho, summarising the main points of the workshop. The refreshments after each workshop gave the parents an opportunity to talk to the teachers about their children in an informal context.

Figure 1 below provides a sketch of the project model. In such a model, the intervention programme does not deal directly with the learners, but it is assumed that the learners will ultimately benefit, via the resource and capacity development components.

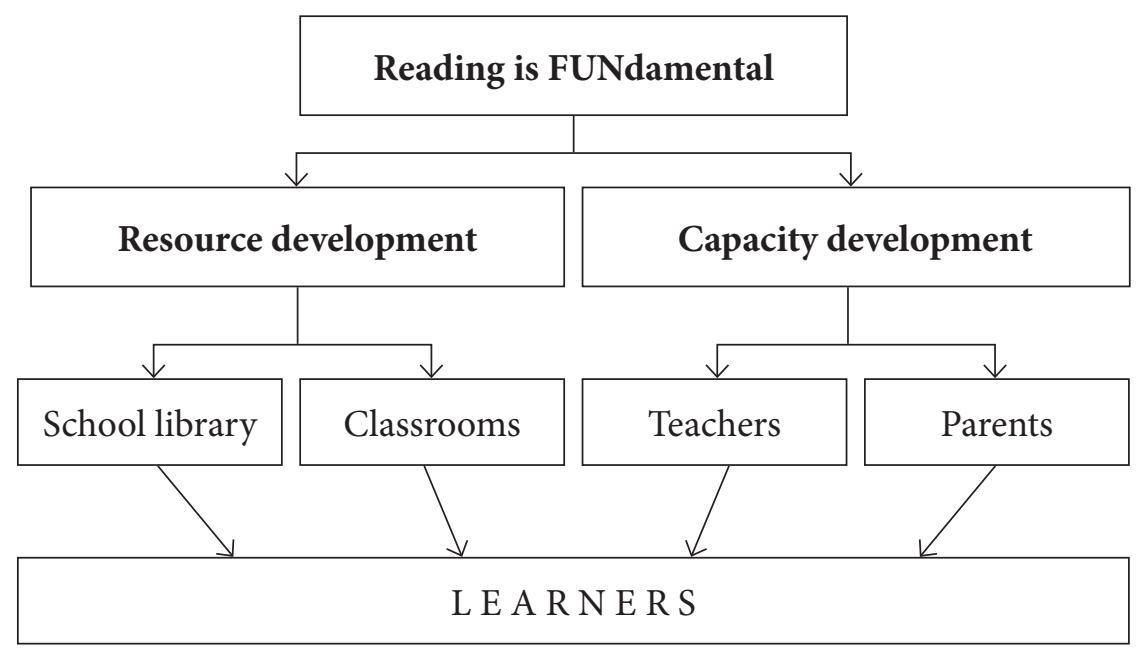

Figure 1: Model of multi-level reading intervention programme

\section{Aligning the project with school management}

To ensure that the project was kept central to the life of the school the project facilitator met with the principal once a week to gain and give feedback about implemented project activities, discuss outcomes, plan and organise scheduled activities, problem-solve around obstacles, and sustain commitment to and enthusiasm for the project. In addition, the project facilitator aimed to promote ownership of the changes and tried to ensure management responses 
that could lead to the institutionalisation of new, beneficial practices such as target-setting and monitoring, scheduling of more time for reading, time management, and ongoing in-service development.

\section{Feedback and discussion sessions}

Feedback/discussion sessions involving staff and the research team were a regular feature of the project. The principal and staff talked about what they had done with regard to reading in the past term, problems they encountered and how they dealt with them. At end-of-term meetings, written reports from the librarian, HOD for the Foundation and Intersen Phases, the principal, the project facilitator and research co-ordinator were presented.

\section{Monitoring the effects of the project}

To gain insight into the way in which the project impacted on the learners, the teachers, the parents, the classrooms and the general functioning of the school, various assessment tools, both quantitative and qualitative, were employed.

Besides pre- and post-test literacy assessments of learners which track learner performance, weekly classroom observations by the project facilitator helped to reveal school practices. This procedure was discussed at the start of the project and all staff members agreed to it. During the first year, classroom literacy observations were undertaken primarily in Grade One and Grade Seven. During the second year of the project these classroom observations were extended to all the grades. An observation schedule was used to document various observable literacy aspects of classroom life pertaining to the physical features of the classroom, the resources available, the literacy activities that the teachers and learners engaged in, the way in which and the extent to which storybook reading was used in class and the extent to which learners seemed engaged in literacy tasks. Less visible aspects of literacy practices were also considered, for example, the attitudes and values that teachers appeared to attach to reading and other literacy activities. Teachers were given copies of the observation schedules and were encouraged to discuss any aspect thereof with the project facilitator. The observation schedules provided a framework for documenting changes in literacy behaviours over time, and for providing teachers with feedback (see, e.g., the 'pencil' discussion above). Teachers could also use the schedules to start evaluating their own classrooms and reflect on their own literacy instructional practices.

School resources and practices were further documented through photographs which were taken regularly by the project facilitator, through informal 
discussions held with teachers which were recorded in the facilitator's field notes and through written reports presented by project participants.

\section{Project Outcomes}

Since reading skills form the basis on which all subsequent school-based learning is built, reading levels are often used as an index of how well schools are functioning (Salinger and Campbell, 1998). In this article we first look at whether the intervention had an impact on the reading levels of learners. Since changes in learner performance are not the primary focus of this article, these results are only briefly covered. We then examine other non-academic outcomes of the intervention in the light of these outcomes. From these insights we draw conclusions regarding the impact of the intervention on the school's functioning and effectiveness.

\section{Reading Outcomes}

The Grade Seven learners were assessed twice every year, at the beginning of the year and then again towards the end of the year. To allow for valid comparisons across languages, the same tests were given in English and in N Sotho, with the N Sotho tests administered at least four weeks after the English tests to minimise memory effects. Because the tests are the same in both languages, different sets of pre- and post-tests were designed.

The reading test included a variety of test tasks, including multiple choice questions based on an expository text, a cloze activity, the resolution of anaphors in paragraphs, and questions based on maps/graphs. Further methodological details and analyses of the impact of the project on learner performance can be found in Pretorius and Mampuru (2007) and Pretorius and Currin (2010).

The results of differences between pre- and post-test reading performances for both English and N Sotho are shown in Figure 2. As can be seen from the graphs, the results show a slow but steady increase in English reading scores. Surprisingly, in all three years the learners' $\mathrm{N}$ Sotho reading comprehension lagged behind English and never rose above $40 \%$. 


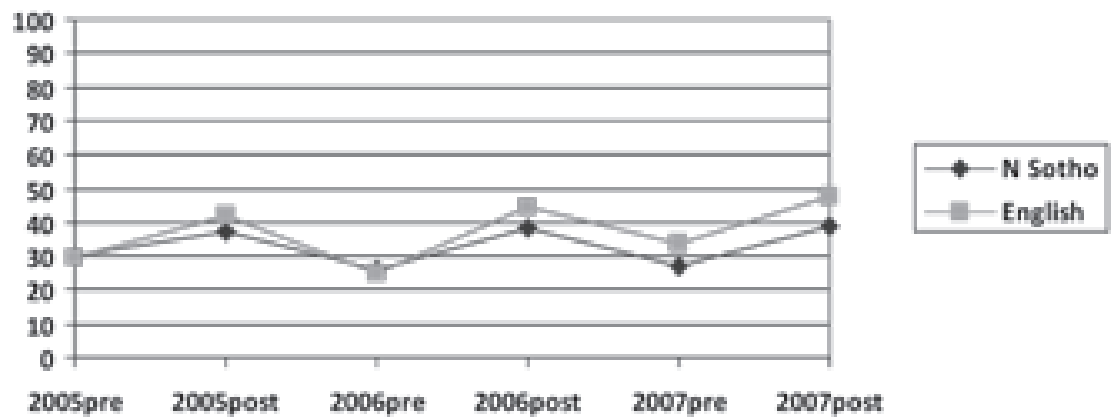

Figure 2: N Sotho and English reading Comprehension - pre and post-test results 2005-2007

Even though the reading mean in both languages remained low, more learners were starting to show stronger reading abilities. Post-test results showed a gradual shift to slightly higher levels of performance across the board at both ends of the performance spectrum. For example, by November 2005, the number of very weak readers in English (below 20\% comprehension) had dropped from thirty-one to six, and whereas only one student scored above 60\% in English reading comprehension in the pre-test, in November 2005 there were eighteen students who scored above 60\%. In 2006 there were again at least thirty 'nonreading' learners who scored less than $20 \%$ in the English reading test and only two learners who obtained above $60 \%$ in the pre-tests; the nonreaders dropped to five in the post-test while at the other end of the spectrum thirteen learners obtained more than $60 \%$ in English reading by the end of that year.

Despite these modest achievements, the low mean reading score of $47.8 \%$ for English and $38.7 \%$ for $\mathrm{N}$ Sotho after the third year point to the challenges that still lie ahead for schools like this one.

\section{School Outcomes}

If the Grade Seven reading skills improved slowly and modestly during three years of intervention, what was happening elsewhere in the school? An analysis of the other data collected over the three years suggested that some changes in areas such as resources, teacher capacity, teacher understanding and attitudes, as well as school functioning and management were being made. 


\section{Resources}

Changes in school resources can be tracked relatively easily since print resources are observable and quantifiable. This was an area which yielded some encouraging changes: from a poor print environment the school slowly created a more visible and richer literacy environment. Resources can also be evaluated in terms of qualitative factors such as accessibility, appropriateness and relevance. These are all issues which will be touched on in the sections below.

The school library: From an initial motley collection of 200 books after the weeding process, the school library boasted a modest collection of over 3,500 books by the third year, and the school set itself the goal of doubling this number in the years ahead. Most of the books in the collection were children's fiction; the non-fiction collection still needed to be built up considerably. Only about 180 books in the collection were in N Sotho (of which there were about 129 titles), and nearly all these were storybooks for children under the age of about ten. There were very few storybooks in $\mathrm{N}$ Sotho for teenage readers. Despite an active policy to buy as many books in N Sotho as possible, the availability of these books was limited. It was also very difficult to find nonfiction books in N Sotho.

By the second year the lending system was fully functioning and learners could take out books during break times and after school. The library had a regular stream of users on a daily basis. Learners at the school had easy access to books in a way that they never had before. Many of the books were interesting, age appropriate and relevant to primary school children.

Volunteer Grade Six and Seven learners served as library monitors and had 'library monitor' badges. They became familiar with the general organisation of the library, and helped the librarian during break and in the afternoon. They were also expected to serve as reading role models, and to this end were issued with 'book journals' in which they recorded the books they read and provided brief summaries of them.

Even though learners were using the library regularly, teachers were doing so to a far lesser degree. It became clear that information literacy was an unfamiliar terrain for many teachers.

Print resources in the classrooms: Initially, classrooms were poor print environments. During the first year of the project literacy resources for the Grade One classrooms were built up (e.g. books, puzzles, games, charts, bookshelves, book corners). Thereafter other grades followed suit. The teachers, especially in the Foundation Phase, started making and displaying alphabet and weekly/ 
monthly charts, flashcards and labels for objects in the classroom. The Foundation Phase classes had very small, modestly stocked book corners and physical manifestations of literate activities became more visible, such as storybooks, charts, flashcards, labels, and examples of learners' drawings and writing on the wall.

One of the Grade Seven teachers started a small classroom library with books in both English and N Sotho 'rescued' from the library weeding process, and magazines borrowed from friends and family. She encouraged her learners to read from this collection once their work was completed. She also arranged for the Grade Seven learners to arrive at school early on a voluntary basis to read books before school started.

Some classrooms were 'freshened-up' and, where possible, rearranged to promote an awareness of books and reading. On the whole, there was a greater effort to display print in classrooms and motivational slogans about reading appeared in each classroom. However, the collection and display of print resources in classrooms depended to a large extent on the initiative taken by individual teachers. Some teachers showed enthusiasm and ingenuity in building up their modest resources and in the management and control thereof while others seemed indifferent or reticent.

\section{Capacity}

One of the factors that contributes to the continued normalisation of literacy underperformance in poor schools is that of teacher knowledge, skill and expectations. Although some aspects of changes in teacher capacity are observable (e.g. changes in classroom management and activities), there are also aspects that are not directly observable, such as the sense-making and valuing that go on inside teachers' heads. In this section we describe some of the changes that were observed.

Teachers: It was clear at the start of the project that teachers lacked serviceable knowledge of what reading entails, how it develops and factors that impact on its development. Teachers also lacked a wider frame of reference to assess learner performance and their own instructional activities. Although the teachers were aware, in a general way, of OBE assessment standards, there seemed to be a large gap between policy and classroom practice. There was also no monitoring of learners' reading progress at the school.

Teachers' limited knowledge led to low expectations. This was tellingly demonstrated when, at the start of the project, one of the Grade One teachers 
expressed the hope that by the end of the year "some" of her learners "would be able to read some words". When it was suggested that many should already be reading short simple texts earlier in the year, she expressed polite disbelief. After spending a morning at a high functioning school where she observed Grade One students reading storybooks in the second term already, she was inspired to aspire to the same level of performance. By raising her expectations of what her learners could achieve, she worked to that goal. Assessments of her Grade One learners in November that year testified that some of her learners could read aloud quite fluently in N Sotho from little storybooks. The department Head of the Foundation Phase remarked that this was not something that they would have expected from Grade One students in previous years.

The general impression was that the teachers were, after three years, certainly far more aware of reading and its role in academic performance than at the start of the project. In turn, they talked about the importance of reading to their learners and exhorted them to read more. There was now a dialogue about reading that had moved into the domain of public discourse at the school in quite a noticeable way.

It is more difficult to determine the extent to which teachers became better reading teachers themselves. It was observed that teachers attempted to apply some of the techniques aimed at developing reading competence which had been covered in the workshops. Initially, literacy activities seemed to take the form of communal activities, with choral chanting of syllable lists from the chalkboard or the whole class reading aloud in unison from textbooks with little attention paid to meaning or enjoyment. Attention to the development of reading as an enjoyable individual meaning-making accomplishment seemed to play a minor role in the classrooms. The teachers also seemed overwhelmed by the magnitude of some of the learners' reading problems and tended to adopt a strategy of ignoring the weak learners and teaching to the class as a homogenous group instead. Given the large classes and cramped classroom conditions, both these approaches were clearly coping strategies. These approaches may also reflect social attitudes to literacy, where reading is perceived primarily as a shared social activity. Sitting alone to read a book for entertainment is not common practice among all communities, even where there are other kinds of engagements with literacy (Heath, 1983) and so classroom activities that specifically promote individual development of this skill may not be given high priority.

Some teachers started treating their classes as comprising heterogeneous groups of readers and they started to monitor (albeit in an unsystematic way) the individual reading progress of their learners. Some also provided more opportunities for individual learners to read aloud in class. Calling on good 
readers to read excerpts aloud from a storybook also became a regular feature of school assembly, thereby affirming individuals with good reading abilities. One aspect of classroom life that changed was that teachers regularly started incorporating storybook reading into their classroom routines with questionanswer routines that tapped into the meaning of the story, and the children clearly loved these sessions. This was particularly evident in the Foundation Phase.

Even though the teachers were tentatively extending their repertoire of teaching methods and materials it was clear that there was still much ground to cover. Here, too, some individuals responded to change more positively and proactively than others.

Grade One classrooms: Both Grade One teachers were determined to enable all their learners to read and now worked collaboratively towards achieving this outcome. In addition, reading instructional methods changed as a result of the workshops and collaboration with the two effective schools who served as reading role models.

Emphasis was placed on getting 'the basics' right, so a sound phonics approach was encouraged, but this was complemented with storybook reading. Even though much of the phonics work was taught and practised from the chalkboard, more opportunities were created to get learners to read extended discourse (e.g. short little stories) for the purposes of consolidation and practice. Teachers initially commented that they perceived storybook reading to be frivolous, to be engaged in only after the 'proper work' was done. During the first year it was observed that these teachers were persuaded that the reading of storybooks could be effective when combined with phonics. As the year progressed it was clear that learners had become acquainted with books and handled them with greater familiarity. Secondly, fun became associated with books as these teachers integrated storybook reading into their daily routines. By the third year storybook reading became a more intricate and productive engagement with the learners. The teachers also arranged for the Foundation Phase learners to take storybooks home in special bags on a designated day each week for someone at home to read to them or to listen to them read. In this way parents were encouraged to support the development of their children's reading. However, reading homework on an everyday basis was still not implemented.

Grade Seven classrooms: During the course of the first year, both Grade Seven language teachers reported that they had become convinced that the reading abilities of their learners impacted on their academic performance. One teacher introduced a system of learners completing 'Reading Records' which 
had been encouraged by the project. She herself joined a community library, and became a 'reading granny' at home. She began to read stories for fun to her learners. During the third term a visiting researcher commented on the 'habit' the class had of taking books from the display unit when they were waiting for others to complete tasks. This was not something that had occurred when she had first visited the class at the start of the project.

\section{School-Parent Relationships}

It is difficult to assess the impact of the Family Literacy workshops on parents or on learners' subsequent literacy accomplishments since there were no follow-up case studies of specific parent-child dyads. This is clearly an area that merits further research. Attendance of parents at workshops did not show any relationship to learner performance - parents of weak readers as well as good readers attended the workshops. However, the Family Literacy workshops did seem to be having an impact in some ways.

Firstly, the parent workshops provided an ideal opportunity to showcase the teachers and to affirm the positive things that they were doing at the school. It is assumed that, if parents become aware of the teachers' commitment to their children, they may feel more committed to supporting their children and the school. Some teachers indeed reported that more parents, especially in the Foundation Phase, were playing positive support roles at home. There was more help with homework and some learners were given more opportunities to read or develop their literacy skills outside the classroom. Some teachers in the Foundation Phase observed that children whose parents actively assisted with reading at home progressed more rapidly than children who had no exposure to literacy activities in their homes.

Secondly, some of the issues that emerged at the workshops pointed to parental needs that require attention, for example, the need for parents to have a nonthreatening forum where they can discuss good parenting practices, discipline in the home, and ways of instilling a culture of reading and homework at home that mirrors what the school is trying to achieve.

There was also freer and more creative participation of the teachers in the Family Literacy workshops than when the project began. This suggested that some teachers were taking greater ownership of these workshops, an important development for the long term sustainability of school-parent ties. By the third year four teachers had been sponsored with project funding to complete a certificate course on Parental Involvement. One of the teachers even obtained a distinction in the exams. Investment in this kind of 'in-service training' will 
hopefully contribute to the sustainability of the family workshops even after project completion.

\section{School management}

When the project first started, Batho Pele was not what Hopkins et al. (1997) classify as a Type 1 school (i.e. dysfunctional schools that are resistant to change); it was functioning, albeit at a modest level, at both school and classroom levels and there was a desire to improve. This will to improve as well as inherent and enhanced capacity did indeed translate into observable changes which demonstrated some shifts in school ethos, governance, leadership and management.

Firstly, there was a sense of a more 'empowered' school: some teachers used and adapted teaching resources gained from the workshops or from their 'twin' school. There was a new awareness of the close association between reading levels and learners' academic performance which led to more frequent discussions about how the school could overcome its reading problems and some strategies were introduced. For example, teachers, particularly in the Foundation Phase, reviewed their policy for teaching reading in an effort to establish the basics more effectively and set more demanding reading targets for their learners. On its own initiative the school celebrated Reading Week each year at assembly without prompting from the project team. It was also reported that school managers and teachers now used school meetings to encourage parents to assist their children to build their reading skills in the home and the governing body exhorted parents to encourage children to read.

Expenditure of the school fund was re-prioritised in order to pay for library needs - a further example of the important position reading had assumed in the school. In addition, for the first time the recommended $10 \%$ of the Learner Support Material budget was allocated by the school to swell the library book collection. In the past it was used for stationery and other expendables. Leadership became more 'dense' and shared with the introduction of the functioning library committee (teachers), the library monitors (learners) and teacher leadership in the Family Literacy workshops. A more effective system of control in communicating with parents also emerged. Return slips were added to letters being sent home. The principal saw the project as a vehicle for concomitantly addressing other problematic academic and management issues. The principal also adopted the vision of the school having a reading culture and its learners reading at acceptable levels (if not now, then at least within the next few years) and teachers, on the surface, appeared to have 'bought into' this vision and the revised timetable started each day with a half hour reading period. 
The teacher allocation was changed to allow the Grade One classes to be smaller (35 learners) than in the past (40 or more learners), so as to enable the achievement of a good foundation. Some of the language educators across the grades started grouping learners according to reading levels and, in this way, tried to provide extra help to weaker readers and extension to the stronger ones. Learners with severe reading problems were referred to the District but, sadly, satisfactory responses were not found.

Some changes were slow to emerge, some were sustained, and some were short lived. Not all classrooms became print rich. Even though the literacy period visibly appeared on the timetable, the period itself was not always fruitfully utilised for literacy activities to maximum effect and teachers were not always in their classrooms for this period. In addition, the library was not integrated by teachers into their delivery of the curriculum. Furthermore, despite project efforts, the systematic and regular assessment of learners' reading by teachers did not take root. The early detection of and support for reading problems did not become common practice. Lesson presentations were often superficially planned and prepared. Although classwork and homework appeared to be more frequently given, the tasks appeared to be undemanding and inconsistently managed. Teachers were often absent or out of the classroom for one reason or another, and maximum use of time and 'opportunity to learn' were often lost on a daily basis.

\section{Reflecting on changes and school effectiveness}

In this article we have attempted to document the changes that a multi-level reading intervention programme brought about in a high poverty, modestly functional but poor-performing school during the first three years of implementation. We have also identified some school practices which were largely unaffected. We now reflect on change and stasis and the impact of the project on school functioning and effectiveness and, in this way, address the question posed in the title of this article: Can a literacy intervention lever school change?

Learners who come from high poverty homes pose special challenges to schools and their teachers. Schools and intervention projects can never change the economic and social circumstances of the learners; instead they need to create an optimum environment that fosters a culture of learning and teaching excellence. This project has focused on trying to improve the school's ability to build learners' reading performance which is key to their academic success and potential for improving their future socioeconomic conditions. In the process 
of trying to achieve this it was observed that additional outcomes emerged which impacted on other levels of school functioning and effectiveness.

The formal assessments indicated that the reading levels of learners were slowly and modestly improving, and at the Grade Seven level this correlated significantly with academic performance (see Pretorius and Mampuru, 2007, Pretorius and Currin, 2010). Since reading levels are considered to be an indicator of school effectiveness it can be said that the intervention made an impact on Batho Pele Primary School's effectiveness and will, in time, help the school reach its goals. However, these changes happened slowly, and the overall reading levels of the learners, despite three years of intervention, were still low. There were also some learners coming into Grade Seven each year with 'non-reading' status, suggesting that the development of reading in the lower grades was not yet happening effectively and that reading problems in the earlier grades were not being addressed.

In addition, observed multi-level changes at the school that were identified earlier in this article (e.g. awareness, positive attitudes, ethos, resources, capacity, parent involvement, leadership, school and classroom management, collaborative lesson planning, reading and writing homework ) and which can be directly attributed to the intervention, coincide with many factors identified in SE research as contributing towards school effectiveness. Importantly, changes emerged on both the school and classroom levels which, as Harris (1998) points out, are critical to the whole school's effectiveness. Hence, it can be said that the project intervention had contributed towards improved effectiveness of the project school.

Changes may appear to be modest and certain key improvements at the school level which are associated with school functionality and effectiveness are yet to be realized. These include the attainment of sufficient textbooks (resources), increased 'opportunity to learn' time (ethos, management), effective target setting for reading improvement with regular monitoring and evaluation (leadership and management), excellence in teacher preparation and delivery; regular and quality assessment, diagnostic analysis of results and remediation (teaching). Many of these factors were beyond the scope of the intervention. In addition, it became clear that changed attitudes and the adoption of new behaviours focused on raising literacy levels are unevenly implemented by individuals and across grades. This may relate to different levels of personal empowerment and skills, unhelpful attitudes, inadequate leadership or management. 


\section{Lessons learned}

There are no easy solutions to the challenges that high poverty schools face, especially when such schools also have a history of relative ineffectiveness. During the three years of project implementation at Batho Pele it became evident that the introduction of the multi-level reading intervention produced planned reading improvement but also induced (and necessitated) unplanned outcomes at other levels of the school. Some changes suggested that the school was slowly becoming a more functional and effective school. In addition, these changes also showed unequivocally that a reading intervention programme in a high poverty context can never simply be a reading intervention; an intervention permeates all aspects of school life, large and small. For example, the decision by the principal not to tolerate short, blunt pencils lead to a bigger realisation that the general laxity at the school negatively affected learning in the long run and this resulted in a campaign to improve discipline in the school. All this was triggered by the project's aim to improve literacy development. Yet a term later, short blunt pencils reappeared in the classrooms again. Although attention to small instructional details in the classroom is vital to effective teaching and learning, this was not always consistently carried out or sustained over an extended period in the school.

The intervention model did not 'engender' or enable certain factors which have been identified in research as key to school effectiveness, namely 'maximum opportunity to learn' time; enough suitable textbooks and support materials; excellence in teaching; effective and informed target-setting, monitoring of quality and standards, and evaluation; changed practice evenly applied throughout the school. The absence of these factors could explain why significant improvements in reading scores have been slow. Multiple reasons for the absence of these factors relate to imperfect or inconsistent implementation of the project model, inherent problems in the school itself, the education system, and some teachers feeling overwhelmed by their workloads or by the learners' literacy (and other) needs.

There are a host of important variables that contribute to the effective functioning of a school and the successful accomplishment of literacy. The project is powerless to change many elements within the school and the broader educational system. Learners and schools in high poverty contexts require skilled and knowledgeable teachers and extra educational resources to counteract the effects of poverty on learning. A small-scale reading intervention project that relies on limited external funding can only attend to some of the 'broken windows' on this educational train. In doing so it can, however, adjust its model to try to overcome some of the obstacles and find ways to ensure better quality and consistency in project implementation and, in this way, accelerate 
change. For example, capacity development via the workshop model is not always effective for teachers who need to change their classroom practice but are unsure of how to do so. In such cases, approaches and strategies suggested in workshops do not readily cascade into the classroom. A stronger emphasis on mentoring and support within the classroom is needed to complement the function of workshops. We propose the inclusion or strengthening of the following:

- a greater focus on teacher support and development within the classroom, especially lesson planning and the effective utilisation of textbook and support materials;

- strategies to greatly improve 'opportunity to learn' time (i.e. time on task);

- provision of sufficient, suitable textbooks/support materials so that each child has his/her own copy to read and take home to do homework or study from;

- building the capacity of HODs/middle managers to fulfill their leadership, management, monitoring and quality management roles effectively;

- strengthening levels of empowerment, pro-activity, self-belief and resilience of teachers;

- attention to the many learners who urgently require remedial assistance.

It can be concluded that the multi-level, reading-focused model of the 'Reading is FUNdamental' project can be instrumental to some extent in raising a school's effectiveness. The experience of the project, however, also indicates that for the intervention to increase its impact and potential for sustaining the changes, the model should be adjusted to include additional planned outcomes and strategies to achieve these.

\section{Acknowlegements}

The 'Reading is FUNdamental' project, from which this research derives, was funded by the DG Murray Trust and the National Research Foundation. The opinions expressed here are not necessarily those of the funders. Sincere thanks to all the learners and staff at the school for participating so generously and willingly in the project. 


\section{References}

Allington, R.L. 2002. Big Brother and the National Reading Curriculum. Portsmouth, NH: Heinemann.

Bradley, R.H. and Corwyn, R.F. 2002. Socioeconomic status and child development. Annual Review of Psychology, 53: 371-399.

Christie, P. 1998. Schools as (dis)organisations: The 'breakdown of the culture of learning and teaching' in South African Schools. Cambridge Journal of Education, 28(3): 283-300.

Christie, P. and Potterton, M. 1999. "Resilient" schools: A South African Study. In Creating People Centred Schools, J. Gultig, T. Ndhlovu and C. Bertram (eds). Cape Town: Oxford University Press.

Department of Education, 2003. National report on systemic evaluation: Mainstream Foundation Phase. Pretoria: Department of Education.

Department of Education, 2005. Systemic Evaluation Report: Intermediate Phase Grade Six. Pretoria: Department of Education.

Elley, W.B. 1991. Acquiring literacy in a second language: The effect of book-based programmes, Language Learning, 41: 375-411.

Gladwell, M. 2001. The Tipping Point: How Little Things can Make a Big Difference. London: Abacus.

Gustafsson, M. 2005. The relationship between schooling inputs and outputs in South Africa: Methodologies and policy recommendations based on the 2000 SACMEQ dataset. Downloaded in May 2007 from http://www.sacmeq.org/links.htm

Harber, D. and Muthukrishna, N. 2000. School effectiveness and school improvement in context: The case of South Africa. School Effectiveness and School Improvement, 11: 421-434

Harris, A. 1998. Teaching and Learning in the Effective School. Gateshead, Tyne and Wear: Athenaeum Press.

Heath, S.B. 1983. Ways with words. Cambridge: Cambridge University Press.

Hopkins, D., Harris, A. and Jackson, D. 1997. Understanding the school's capacity for development: Growth states and strategies. School Leadership and Management, 17: 401-411.

Howie, S.J. 2002. English Language Proficiency and Contextual Factors Influencing Mathematics Achievement of Secondary School Pupils in South Africa. Unpublished PhD thesis. Enschede: University of Twente.

Jordaan, C. 2004. Exploring the characteristics of effective schools: A study conducted in a sample of seconday schools based on their 2002 Grade Twelve examination results. Unpublished paper presented at the 2004 Gauteng Department of Education's Educationally Speaking Conference, 2004, Pretoria.

Levin, H.M. and Lockheed, M.E. 1993. Effective Schools in Developing Countries. Stanford Series on Education and Public Policy. Washington: Falmer Press.

Maden, M. (ed). 2000. Success Against the Odds - Five Years On. London: Falmer Press.

Muller, J. and Roberts, J.A. 2000. The sound and the fury of international school reform: A critical review. Report prepared for the Joint Education Trust.

Pretorius E.J. 2005. What do students do when they read to learn? Lessons from five case studies. South African Journal of Higher Education 19(4):790-812. 
Pretorius, E.J. and Mampuru, D.M. 2007. Playing football without a ball: Language, reading and academic performance in a high poverty school. Journal of Reading Research 30(1):38-58.

Pretorius, E.J. and Currin, S. 2010. Do the rich get richer and the poor poorer? The effects of an intervention programmes on reading in the home and school language in a high poverty multilingual context. International Journal of Educational Development, 30: 67-76.

Salinger, T. and Campbell, J. 1998. The national assessment of reading in the USA. In Assessing reading: Theory and practice, C. Harrison and T. Salinger (eds). London: Routledge. Scheerens, J. 2000. Improving School Effectiveness. UNESCO: International Institute for Educational Planning.

Scheerens, J. 2001. Monitoring school effectiveness in developing countries. School Effectiveness and School Improvement, 12:359-384.

Taylor, N.C. 2007. Equity, efficiency and the development of South African schools. In International Handbook of School Effectiveness and School Improvement, T. Townsend (ed.). Dordrecht: Springer. 